\title{
A influência da Vinícola Villa Francioni na paisagem turística de São Joaquim (Santa Catarina, Brasil)
}

\section{The influence of Villa Francioni Winery on São Joaquim (Santa Catarina, Brazil) tourism lansdcape}

\author{
Romualdo Theophanes de França Júnior (FRANÇA JR., R. T.) ${ }^{*}$ e \\ Cristiane Silva (SILVA, C.) ${ }^{* *}$
}

RESUMO - Essa pesquisa objetivou analisar e compreender a influência da Vinícola Villa Francioni como atrativo turístico do município de São Joaquim (Santa Catarina, Brasil) apresentando subsídios como instrumentos para gestão adequada e planejada da paisagem turística, no contexto de uma perspectiva crítica e estratégica envolvendo a atividade do enoturismo, como parte integrante da economia local. Compreende uma abordagem metodológica exploratória, partindo dos conceitos que se referem à paisagem como atrativo e, ao espaço geográfico através dos seus elementos naturais e elementos construídos. Também envolveu a avaliação sistêmica da edificação e seu entorno, decifrando a originalidade do cenário e identificando a sua importância para a comunidade residente. Vislumbra-se, portanto, ampliar o conhecimento bibliográfico sobre a temática e proporcionar dados e informações que possam orientar a dinâmica decisória de políticas públicas para requalificação do cenário, seguindo o conjunto de fatores que devem ser tratados e planejados simultaneamente, de forma a enriquecer e valorizar a história e cultura local como forma de potencializar o desenvolvimento do turismo através da paisagem.

Palavras-chave: Paisagem Turística; Enoturismo em São Joaquim; Vinícola Villa Francioni; Valoração Cultural e Histórica.

ABSTRACT - The main purpose of this present research was to analyze and understand the influence of Villa Francioni winery as a tourist attraction of São Joaquim (Santa Catarina, Brazil), presenting subsidies as instruments for an adequate and planned management of the tourism landscape, considering the context of a critical and strategic perspective involving the wine tourism activity, as a part of the local economy. This present work also comprehends an exploratory methodology, which takes into account all the concepts related to the landscape as attraction and the geographic space

\footnotetext{
* Formação: Graduação em Engenharia Civil pela Universidade do Estado de Santa Catarina (UDESC), Mestrado em Infraestrutura e Gerência Viária pela Universidade Federal de Santa Catarina (UFSC) e Doutorado em Administração e Turismo pela Universidade do Vale do Itajaí (UNIVALI). Atividade profissional: Docente da UDESC. Endereço físico para correspondência: Rua Jacob Eisenhuth, 512, ap. 1202 (Atiradores). CEP: 89203-070 - Joinville - Santa Catarina (Brasil). Telefone: (47) 9108-1515. Email: romaphanes@gmail.com

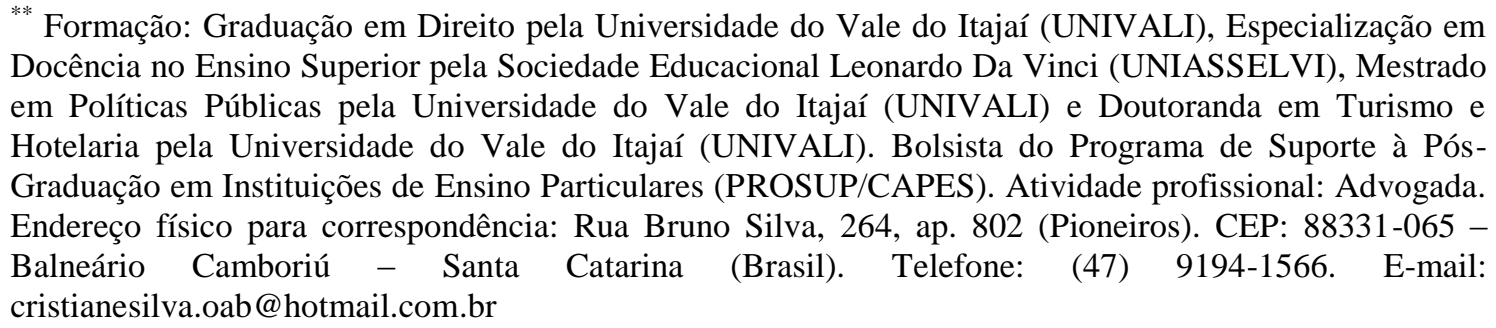


through its natural elements as well as the built ones. It also involved a systemic evaluation of edifications and their surrounds, deciphering the scenario originality and identifying its importance to the local residents. Therefore, it is important to enlarge the bibliographic knowledge about this presented theme, as well as provide data and information that could guide the operative dynamic of public policies for the scenario requalification, following a set of factors that must be treated and planned simultaneously, in a way of enriching and valorizing the local history and culture, as a way of potentiating tourism development throughout the landscape.

Key Words: Tourism Landscape; Wine Tourism in São Joaquim; Villa Francioni Winery; Cultural and Historical Valuation. 


\section{INTRODUÇÃO}

É como atividade eminentemente social que o turismo tem marcado setores da economia e da vida cotidiana das pessoas. Os interesses na atividade turística são os mais diversos, como por exemplo: entradas de divisas para um país, status das cidades e de seus administradores, disputa por fatias de recursos públicos, criação de empresas especializadas, benefícios fiscais, qualificação e requalificação dos espaços, entre outros fartamente apontados em atuais artigos desenvolvidos pela academia. A disponibilidade de atrativos turísticos é igualmente diversificada, dos quais, citam-se, somente, os de lazer, ecológicos, eventos, culturais, paisagísticos, esportes e enológicos. Portanto, por si estes já representam boa parte da vida e dos recursos turísticos possíveis de uma localidade.

O planejamento da paisagem apresenta-se como uma ferramenta indispensável à compreensão e à sistematização da atividade turística nas comunidades receptoras. Neste sentido, trabalhos em pesquisa que contemplem esta linha de temática são de relevância tanto para a atividade turística quanto para o planejamento municipal como um todo. $\mathrm{Na}$ especificidade da temática, estudar as culturas locais e suas formas de apropriação, responsáveis por parte do turismo, figura como imprescindível para a verificação das possibilidades e das limitações do turismo na área em questão, ainda que em termos teóricos (SOARES; CARDOZO, 2008).

O propósito deste estudo desenvolve-se para analisar a paisagem a partir da Vinícola Villa Francioni em São Joaquim (Santa Catarina, Brasil), e a sua potencialidade para integrar-se ao desenvolvimento do enoturismo.

Para tanto, inicia-se pela abordagem teórica, vislumbrando elucidar eventuais dúvidas e demonstrar alguns entendimentos bibliográficos sobre paisagem turística e sua influência sobre o enoturismo, planejamento e gestão na atividade turística, valoração social da região empreendida, território e atrativos turísticos, entre outros aspectos correlacionados.

Segue-se permeando pelo método descritivo, em abordagem analítica, descrevendo os elementos da paisagem turística em seus aspectos visuais, traçando paralelos relacionados com a cultura, a história, as características geográficas, entre outros enfoques de valores objetivos. 
Registra-se, aliás, que se aplicou também o método dedutivo, uma vez que se partiu de uma investigação não específica, razão pela qual, se estabeleceu uma formulação geral e, consequentemente, apresentou-se as partes desse fenômeno, como forma de fundamentar as considerações gerais, destacando os pontos mais importantes obtidos no decorrer da pesquisa.

\section{A PAISAGEM TURÍSTICA E O ENOTURISMO}

Como uma das atividades econômicas de maior crescimento mundial, o turismo tem na vertente paisagística uma forte possibilidade de atração multiplicadora das economias locais. A recriação da imagem de um município, em geral, desperta para a fixação de políticas de governos e representam investimentos com a aplicação de grande volume de recursos públicos. Para tal, tanto a iniciativa privada como os governos, nas esferas federal, estadual e municipal, buscam no planejamento e gestão da paisagem um forte elemento do planejamento e gestão turística das localidades.

Quando o objetivo dos moradores de uma localidade é o desenvolvimento através do turismo, seu planejamento deve ser apropriado às potencialidades; deve, no sentido normativo, observar, valorizar e conservar os traços culturais locais, presentes tanto nas paisagens quanto no patrimônio construído e nos aspectos imateriais (BESSA et al., 2008).

O turismo motivado pela cultura, tradição e detalhes que envolvem o aroma e o sabor dos vinhos, conhecido como enoturismo, encontra-se em plena expansão nas regiões produtoras brasileiras, notadamente na Serra Gaúcha, no sul de Minas Gerais, na região de São Roque, em São Paulo, e no planalto serrano de Santa Catarina.

O enoturismo é um conceito e um produto ainda em fase de desenvolvimento, com capacidade de desempenhar significativo papel regional, através de sua contribuição econômica, social e ambiental (SERRENHO; AGUAS, 2006).

Mais do que o turismo alavancado pelo vinho em si, o enoturismo é o turismo trabalhado pelos atributos de uma região vitivinícola, onde o visitante deve ser envolvido na culinária regional, no estilo de vida associado e na paisagem física e cultural (HALL et al., 2000). 
Na mesma direção as pesquisadoras Dallanhol e Tonini (2012), defendem que com o crescente interesse pelo vinho, presente no mundo como um todo, o segmento do enoturismo vem ganhando adeptos, caracterizando um fluxo de pessoas em busca não só de paladares, como também de paisagens.

Os lugares turísticos são admirados por suas paisagens. Neles os panoramas da natureza e a visão do homem e sua cultura inseridos no território são prazeres a ser desfrutados e, na maioria das vezes, constituem o motivo condutor do viajante (FRANÇA JR.; SILVA, 2012)

Admiradas como cenários, as paisagens são testemunhos visuais de elementos estéticos e simbólicos construídos historicamente e que quando identificados e apropriados pelo viajante despertam um renovado interesse no lugar visitado (SILVA, 2004).

Com base no entendimento de De Oliveira (1999), a paisagem representa um sistema geográfico formado pela influência dos processos naturais e das atividades antrópicas, configurado na escala da percepção humana. Partindo desta base conceitual, pode-se afirmar que a paisagem turística é uma função dos fundamentos da cultura, da história e do espaço geográfico, natural e construído, no domínio das dinâmicas sociais que criam e transformam as formas.

Para Roberto Boullón (1990), a paisagem representa o conjunto de elementos naturais e artificiais que constituem um território; o que implica na caracterização da paisagem por meio da superposição das áreas edificadas, espaços públicos abertos, paisagismos e monumentos no sítio geográfico local, registrando a atividade do ser humano no ambiente natural.

Ficam implícitas, no contexto, a interpretação e a percepção individual que a paisagem pode causar ao homem e, consequentemente, tornar-se um atrativo turístico vinculado à cultura e à história local. No arcabouço de suas pesquisas, Castrogiovanni (2002) entende que a paisagem é uma realidade cultural, pois não é somente trabalho humano, mas também objeto de observações, inclusive de consumo.

Se a cultura desempenha um papel de filtro variável de um para outro indivíduo e de um para outro grupo social, fica caracterizado que a paisagem turística se constitui em instrumento para ser vivido e vivenciado, por visitantes e por residentes. Não se afirma, aqui, que a paisagem seja exclusiva forma de atração turística, mas que possui 
muito valor no contexto de outros fatores, uma vez que a visão turística depende da visão de cada observador.

A paisagem está diretamente ligada a ideia de espaço, é constantemente refeita de acordo com os padrões locais de produção, da sociedade, da cultura, com fatores geográficos e tem importante papel no direcionamento turístico (YÁZIGI, 2002).

Para que uma paisagem turística consiga dar conta das motivações dos visitantes que a contemplam ou a utilizam necessário é que se realizem estudos para o pleno conhecimento dos elementos que as compõem (CASTROGIOVANNI, 2001).

Tais estudos são fundamentais para que se possa realizar o planejamento e a gestão de uma paisagem turística, pois diante da força da paisagem na escolha do destino turístico os moradores/gestores de muitas localidades criam, restauram, reorganizam, revitalizam ou requalificam as paisagens, transformando-as em destacado atrativo à atividade turística. Nota-se, inclusive, que no enoturismo a paisagem é a fonte inspiradora a proporcionar o espaço do consumo turístico.

O pensamento é compartilhado de Dubrule (2007) quando sintetizou que o enoturismo é a arte de viver, repleto de prazeres; é a integração do vinho com todos os produtos e serviços procedentes da junção do turismo com a vitivinicultura, cuja exigência é a qualidade, favorecido pela existência de belas paisagens.

A discussão sobre o planejamento e a gestão do turismo tende a caminhar na busca de uma visão integrada e mais completa que recebe maior ênfase na teoria sistêmica, que vê o sistema tanto na sua totalidade quanto nas suas relações, e a busca pela sustentabilidade está relacionada a todos os seus elementos: naturais, humanos, sociais, econômicos, políticos-ideológicos, filosóficos, tangíveis e intangíveis, fixos e fluxos, forma e função (ANJOS et al., 2005).

Os aspectos e os princípios da teoria sistêmica e do desenvolvimento sustentável devem estar presentes no planejamento de uma paisagem, com base na conservação do ambiente, natural e construído, nos valores culturais e na melhoria da qualidade de vida das comunidades.

Tanto o processo de planejamento como a gestão da paisagem turística depende diretamente do interesse do poder público, da vontade política, e de trazer a comunidade residente para o processo de desenvolvimento da atividade turística, distribuindo de forma mais equilibrada os resultados positivos. 
Por política pública de turismo pode-se compreender o direcionamento dado pelo governo federal, estadual, municipal ou regional para o desenvolvimento da atividade turística, após ter consultado os representantes do setor turístico e da sociedade (LOHMANN; PANOSSO NETO, 2008).

A política de turismo deve ser estruturada levando-se em consideração que deve embasar-se por três grandes condicionamentos: o cultural, o social e o econômico (BENI, 2002). Fica latente, portanto, que a essas condicionantes deve ser agregado o ambiente e por sua extensão a paisagem turística, como diferencial competitivo em favor do enoturismo.

\section{METODOLOGIA DA PESQUISA}

Trata-se de uma pesquisa de caráter exploratório que busca na análise descritiva a principal abordagem para compreensão e avaliação da Vinícola Villa Francioni, como parte integrante e influente na paisagem turística do município de São Joaquim.

É uma pesquisa empírica, que se caracteriza como um estudo de caso, onde foram descritos os elementos da paisagem edificada, relacionando-a com os aspectos históricos e culturais de sua formação, as características geográficas da região e o ambiente natural em que o município está inserido.

Os dados secundários foram obtidos através da análise de documentos disponibilizados pelas instituições responsáveis pela gestão da atividade turística no município, além de revistas e relatórios institucionais. Com a documentação pesquisada foi possível caracterizar o sistema turístico de São Joaquim, fazendo um breve relato de sua história social, cultural e econômica, bem como sobre a origem e a importância da Vinícola Villa Francioni.

Reconhecendo a preponderância da paisagem turística como atratividade do enoturismo, a avaliação procurou identificar as potencialidades da paisagem edificada enquanto recurso para o desenvolvimento turístico.

Para direcionar o trabalho buscou-se a proposta de observação direta da paisagem com base nas categorias de Roberto Boullón (2002), observando: topografia, forma urbana, configuração das ruas com seus tipos de pavimentação, o tratamento 
paisagístico, padrão construtivo das edificações e seus estilos arquitetônicos, entre outros. No que se refere ao significado dessas áreas gravitacionais, abrangendo logradouros e marcos considerados atrativos turísticos do entorno, tomou-se como referencial teórico a proposta de Lynch (1997).

Ao trabalhar os fundamentos acima se identificou quais os elementos que configuram a paisagem turística local, resultando no desenvolvimento de um sistema de informações que pode inferir na atratividade ou mesmo na potencialidade enquanto recurso turístico do município de São Joaquim, como ferramenta de análise dos vínculos gerados entre o objeto e a ação.

A melhor forma de se determinar um espaço turístico é recorrer ao método empírico, por meio do qual se pode observar a distribuição territorial dos atrativos turísticos e do empreendimento, a fim de detectar os agrupamentos e as concentrações mais proeminentes (BOULLÓN, 2002).

Considerando que a paisagem é captada pelo turista de forma seriada, armazenada em sua memória e avaliada conforme seus valores, a análise deve atentar para as motivações dos visitantes, buscando agregar valor à sua atratividade, sem a descaracterização de sua originalidade, assim como do seu significado para a comunidade local (DE OLIVEIRA; FERNANDES; STACH, 2007).

Fica implícito no contexto, a interpretação e a percepção individual que a paisagem dos territórios turísticos pode causar ao homem e, consequentemente, tornarse um atrativo.

\section{COMPREENSÃO SISTÊMICA DO TERRITÓRIO TURÍSTICO}

A região serrana de Santa Catarina foi colonizada por descendentes de portugueses e espanhóis vindos do Rio Grande do sul e de São Paulo, a partir dos anos de 1750, com o movimento dos tropeiros que levavam gado de Viamão e Santo Antonio da Patrulha no Rio Grande do Sul para as regiões de Sorocaba, Piracicaba e Araraquara em São Paulo (RODRIGUES NETO, 2011).

Os primeiros documentos encontrados, fazendo referência ao povoado que hoje é a cidade de São Joaquim datam de 1868; nessa época, Lages era uma localidade 
regularmente implantada e seu município abrangia as terras circunvizinhas, compreendendo as áreas que atualmente formam os municípios de São Joaquim, Urubici e Bom Retiro (RODRIGUES NETO, 2011).

De acordo com pesquisas do ex-prefeito Joaquim Anacleto Rodrigues Neto (2011), no ano de 1873 o bandeirante paulista Manoel Joaquim Pinto fundou, no distrito da Costa da Serra, a freguesia de São Joaquim de Cruzeiros, momento em que a região recebeu descendentes de italianos e alemães, que se integraram ao processo de colonização. O mesmo autor afirma que como município, São Joaquim foi instalado em 7 de maio de 1887, assumindo sua independência.

Localizado no planalto serrano de Santa Catarina, a uma altitude de 1.353 metros acima do nível do mar, na latitude de $28^{\circ} 17^{\prime} 38^{\prime \prime}$ Sul, e na longitude de $49^{\circ}$ 55'54" Oeste, o município de São Joaquim ocupa uma área total de 1.886 quilômetros quadrados e situa-se a 81 quilômetros de Lages, 136 quilômetros de Tubarão e 229 quilômetros de Florianópolis (SEBRAE, 2013).

O município faz divisa com Urupema ao norte, Urubici a nordeste, Bom Jardim da Serra a leste e sudeste, Rio Grande do Sul ao sul e sudoeste, Lages a oeste e Painel a noroeste. É banhado pela bacia do Rio Pelotas e tem como principais afluentes os rios Lava-Tudo, Mantiqueira, São Mateus, Sumidoro, Antoninha e Invernadinha (BERTONCINI, 2011).

De relevo bastante irregular e solo predominantemente pedregoso, possui temperatura média anual de 13 graus Celsius, sendo considerado um dos municípios mais frios do Brasil, com temperaturas que, no inverno, chegam a alcançar 14 graus Celsius negativos, tecendo ao município a alcunha carinhosa de "Cidade da Neve".

Como os demais municípios da Serra Catarinense, teve sua economia fundamentada na pecuária, na agricultura e na extração da madeira. Atualmente, seus moradores aproveitam o clima propício da região para a cultura de frutas de clima temperado, com especial atenção para a produção de maçã, cujo cultivo movimenta mais de $50 \%$ da economia local, reconhecida por ser uma das melhores do país e exportada para diversos outros países, entre eles Chile, Japão e Espanha (SEBRAE, 2013).

Com uma população estimada pelo censo do Instituto Brasileiro de Geografia e Estatística (IBGE) de 2010 em 25 mil habitantes, o equivalente a 0,40\% da população 
do Estado, o município é a $47^{\mathrm{a}}$ cidade no ranking populacional catarinense; apresenta taxa de crescimento anual de 0,87 e índice de desenvolvimento humano-IDH de 0,776 (IBGE, 2010).

Os primeiros movimentos turísticos foram percebidos pela atração de visitantes ao fenômeno de precipitação da neve, que a cada inverno atinge o território de São Joaquim. No ano de 1978 a festa local da maçã toma corpo nacional e passa a se apresentar como evento a atrair significativo volume de turistas a cada dois anos. Mais recentemente passou a se destacar pela vitivinicultura, com seus vinhos de altitude ganhando espaço e reconhecimento internacional, gerando assim mais um forte atrativo turístico (ACORDE, 2009).

Toda a área em que se localiza São Joaquim é conhecida por seu entorno natural, cheio de amplas zonas verdes, campos divididos por taipas, áreas de proteção ambiental, vales, cachoeiras e rios de corredeira, aliado ao seu patrimônio arquitetônico e cultural, que representam a diversidade étnica dos que a colonizaram.

São Joaquim atrai turistas do Brasil inteiro que buscam o aconchego e as paisagens que o inverno serrano proporciona, que muito lembram às paisagens europeias, com fortes expressões para as taipas de pedra, reservas de xaxim, extensos campos e araucárias.

Mas não é apenas de montanhas cobertas por neve e campos por geada que se sustentam as pessoas que atuam com o turismo do município. Na primavera o destaque fica por conta da floração e do perfume que exalam das cerejeiras e macieiras. No verão a atração é proporcionada pela colheita da maçã, onde o turista participa ativamente do processo. No outono as araucárias chamam a atenção dos visitantes. A produção recente de vinhos de qualidade no município tem impulsionado o turismo e a economia local para um novo momento, e vislumbra retratar no enoturismo a alavanca de desenvolvimento regional a partir das peculiaridades de sua origem e identidade cultural.

Com a finalidade de captar e gerar eventos de alcance regional, nacional e internacional, foi fundado no ano de 2003 o "Convention \& Visitors Bureau de São Joaquim", em cuja atuação vem se posicionando como orgão estimulador e colaborador da Secretaria Municipal de Turismo no estudo e solução de problemas relacionados ao setor (BERTONCINI, 2011). 
Sentindo a necessidade de envolver a comunidade residente no processo de planejamento e formulação de políticas públicas para o desenvolvimento turístico, notadamente na discussão de ideias e na fiscalização dos investimentos públicos relacionados com o setor, foi criado em 2009 o "Conselho de Desenvolvimento Econômico e Turístico de São Joaquim”, constituído pela participação de 13 membros da sociedade civil, um representante do poder executivo e um do poder legislativo (ACORDE, 2009).

No âmbito da administração pública conta, também, com o "Comitê Gestor dos 65 Destinos Indutores do Ministério do Turismo", que tem como atribuição a capacitação da sociedade civil e do poder público municipal para a implantação, planejamento e suporte de projetos que busquem o desenvolvimento do município indutor, direcionando para que se torne um destino turístico com padrão internacional de qualidade (ACORDE, 2009).

No contexto das ações promovidas pelo governo estadual, o suporte é fornecido pela "Secretaria de Desenvovimento Regional - São Joaquim", por meio do comitê temático de turismo vínculado as atividades da Gerência de Turismo, Cultura e Esporte (ACORDE, 2009).

Com altitude e clima favoráveis para o cultivo de uva para a produção de vinhos, pesquisa realizada pela Empresa de Pesquisa Agropecuária e Extensão Rural de Santa Catarina - EPAGRI/SC no ano de 2007, com uma amostra da uva cabernet sauvingnon, colhida em São Joaquim, surpreendeu os pesquisadores pela excelência do vinho obtido. O resultado foi confirmado por dois anos e os dados mostraram que os teores da composição química do vinho eram superiores aos produzidos em outras regiões do Brasil (BERTONCINI, 2011).

Os dados oriundos da pesquisa da EPAGRI (2007) demonstram que o município possui as melhores condições para a produção de uvas cabernet sauvingnon do Brasil e fez crescer o interesse público e privado para a viticultura na região. Neste ínterim a Vinícola Villa Francioni foi pioneira nos investimentos e colhe, além do reconhecimento pelos vinhos produzidos, a vanguarda pelo incremento do enoturismo em Santa Catarina. 


\section{A VINÍCOLA VILLA FRANCIONI}

A tradição familiar e a paixão pela arte da vinicultura foram os ingredientes que estimularam o empresário Dilor Freitas à busca de um terroir em território catarinense; colhendo informações ao redor do mundo, visitando e detalhando as melhores regiões produtoras de vinho e dialogando com conceituados especialistas, o empreendedor adquiriu no ano de 2000 uma propriedade no município de Bom Retiro, onde em 2001 iniciou o cultivo de uvas finas (BLUME et al., 2007).

Visionário, e diante da perspectiva de desenvolvimento do enoturismo, o catarinense Dilor Freitas comprou em 2002 uma grande área a 1.260 metros de altitude em São Joaquim, onde lançou no mesmo ano, além da plantação e cultivo das videiras, a construção de sua vinícola, a Villa Francioni, cuja conclusão deu-se no final de 2003 (LOMBARDO, 2009).

Em 2005 ocorreu o lançamento dos três primeiros vinhos com o rótulo da Villa Francioni, dos quais, um elaborado com a uva cultivada em Bom Retiro e os outros dois com cortes da produção de São Joaquim (BLUME et al., 2007). O fato não pôde ser vivenciado por seu idealizador, pois nos primeiros meses do ano de 2004 havia falecido (CORDEIRO, 2006).

O prédio de aproximadamente 4.500 metros quadrados distribui-se em seis níveis para aproveitar o fluxo gravitacional durante o processo de vinificação, evitando o uso de transferências mecânicas; com engarrafamento automático, a cave dos vinhos encontra-se a quatro metros abaixo do nível do solo e a cave dos espumantes a oito metros de profundidade (LOSSO, 2010).

A uva é recebida no nível mais alto e vai sendo processada nos níveis inferiores. A fermentação do vinho ocorre no quarto piso, de onde é conduzido por dutos de aço inoxidável aos andares abaixo. Os equipamentos de vinificação são de origem italiana, os tanques de fermentação fabricados na Argentina e no Chile e as barricas de carvalho oriundos da França.

Ao destacar a importância da arquitetura adotada para a vinícola, Losso (2010, p. 102), comenta: “a obra arquitetônica da Villa Francioni reafirma o modelo que a vitivinicultura do novo mundo vem aplicando, onde esta serve como elemento atrativo do enoturismo". 
$\mathrm{Na}$ figura 1, pode-se perceber a harmonia dos elementos naturais em face dos elementos construídos. Os vinhedos estão implantados de forma a aproveitar ao máximo a topografia e a drenagem natural do terreno, preservando a paisagem original característica da serra catarinense. Objetivando dar a maior qualidade possível ao produto, percebe-se a presença de cuidados com o solo, a altitude, a permeabilidade, a inclinação, a orientação solar, a limpeza, a amplitude térmica e os índices pluviométricos.

Embora o índice pluviométrico de São Joaquim seja alto, em torno de $1.600 \mathrm{~mm}$, chove pouco no período de janeiro a abril, período em que ocorre a maturação da uva e sua colheita. Outro fator favorável é a insolação no período vegetativo, em torno de 1.600 horas, propiciando a adequada fotossíntese e consequentemente a produção de açucares. A amplitude térmica de $20^{\circ} \mathrm{C}$ é baixa, o que preserva a acidez da uva. Todos os aspectos envolvidos tendem a obtenção de vinhos de boa textura e baixa adstringência.

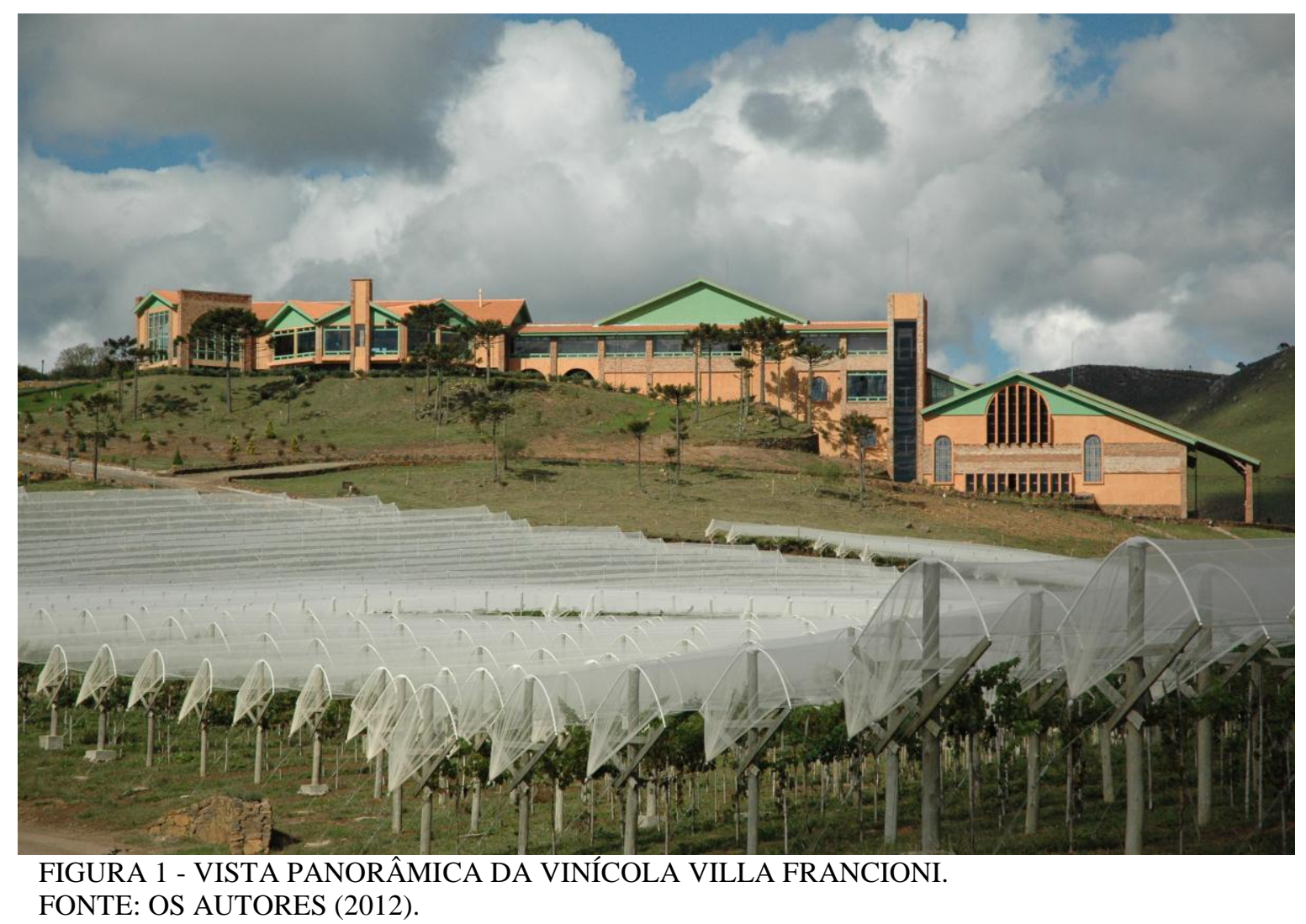


Devido à ocorrência de neve, geada e granizo, notadamente entre os meses de maio a setembro, os vinhedos são produzidos em forma de manjedoura, espaldeira simples tipo $\mathrm{Y}$, e cobertas por uma fina tela plástica com a finalidade de proteger os frutos.

Verificou-se que na construção da vinícola se aplicou madeira e tijolos aparentes com vitrais por todos os lados, visando melhor aproveitamento da luz natural e permitindo a contemplação da paisagem externa. Também, que no interior da bodega se utiliza de peças de demolição, gradis de antiquários, além de lustres, portas e móveis antigos, que remetem às tradições dos colonizadores de São Joaquim e que se fundem à arquitetura contemporânea. Artistas catarinenses pintaram, esculpiram e montaram suas obras de arte nas paredes e jardins da cantina. A figura 2 apresenta uma das vistas interna.

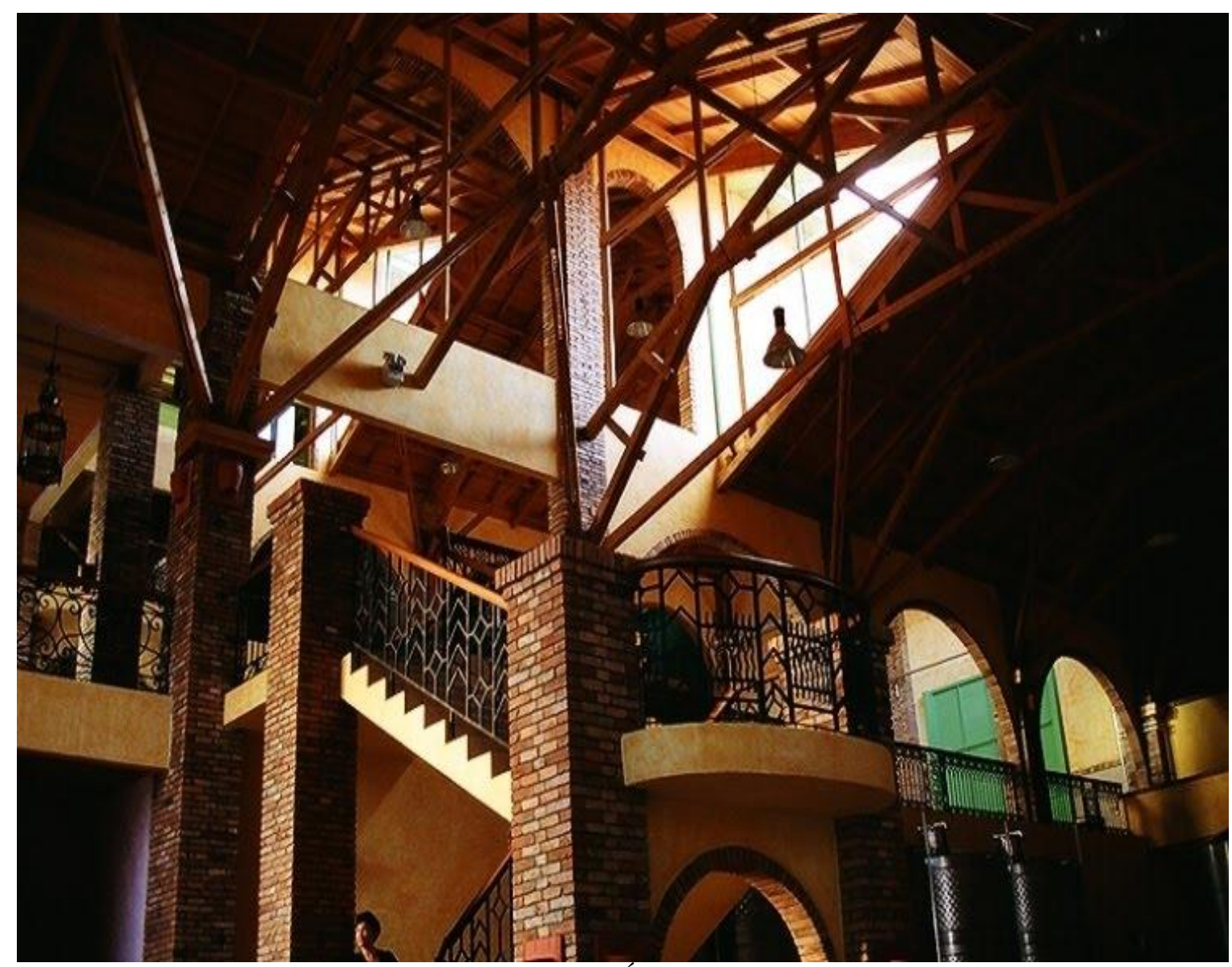

FIGURA 2 - VISTA PARCIAL INTERNA DA VINÍCOLA VILLA FRANCIONI.

FONTE: OS AUTORES (2012). 
Para chegar à vinícola, partindo da área urbana de São Joaquim, segue-se por cinco quilômetros em direção a Lages, pela rodovia SC-438. A rodovia é asfaltada e foi implantada com duas pistas de rolamento de 3,50 metros cada uma e, acostamento em ambos os lados com 1 metro de largura, onde a velocidade de fluxo livre é de $80 \mathrm{~km} / \mathrm{h}$; a pavimentação encontra-se em estado de conservação muito ruim, com os acostamentos comprometidos pela ausência de manutenção e pela vegetação que avança em sua extensão, conforme se pode avistar na figura 3. Ao longo do trajeto, as condições de trafegabilidade não permitem a contemplação da paisagem da região.

Afastada do perímetro urbano, verificou-se que o segmento rodoviário que segue até a vinícola estava apresentando deficiente sinalização de trânsito e, a sinalização turística praticamente inexistia, ao ponto de ensejar muita atenção para se perceber o pórtico de entrada da vinícola Villa Francioni; pois, em que pese toda sua robustez e estética, a atenção de quem trafega acaba por se prender nos problemas da rodovia.

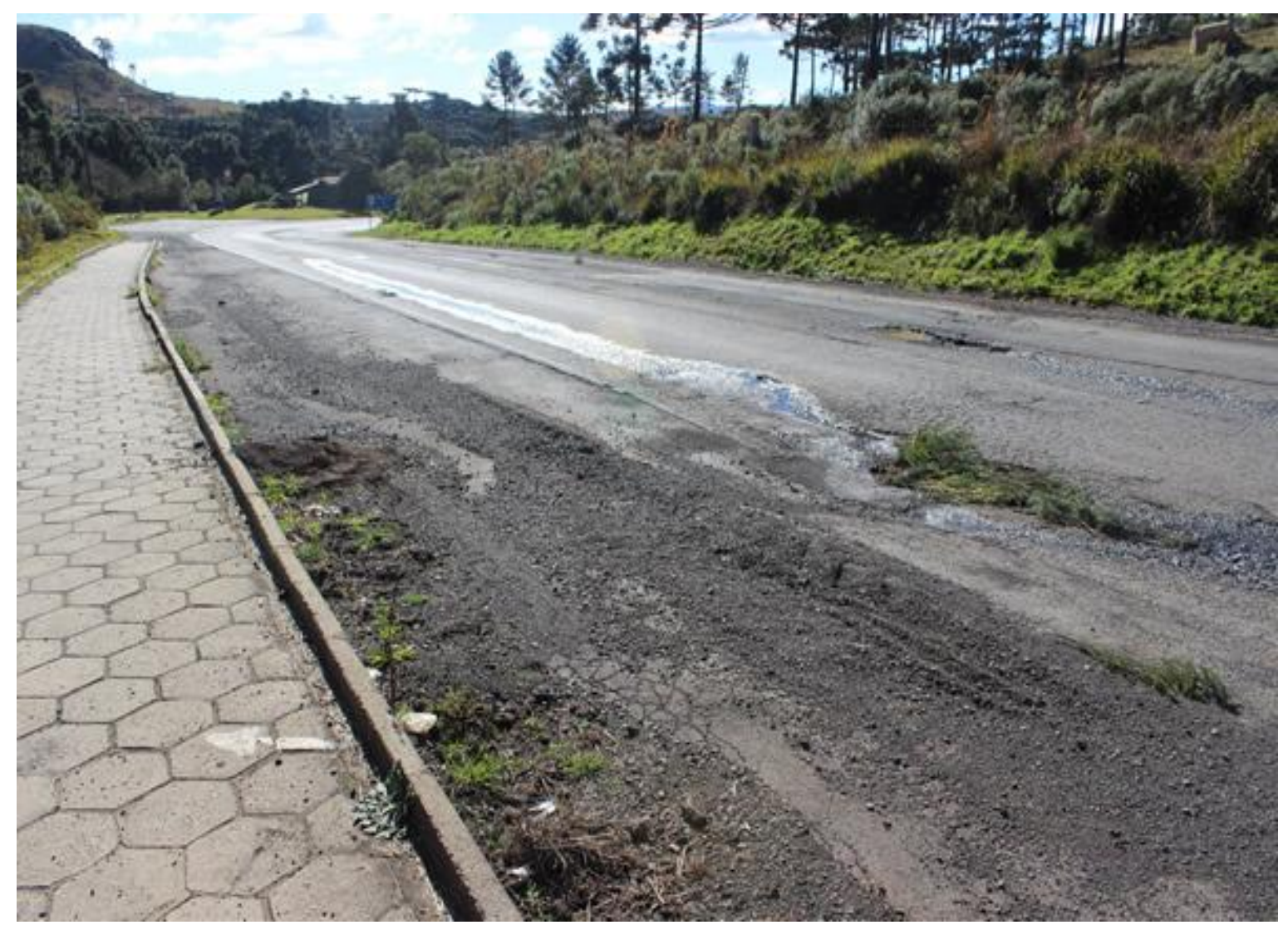

FIGURA 3 - SEGMENTO DA RODOVIA SC-438.

FONTE: OS AUTORES (2012). 
Constatou-se que do pórtico de entrada da vinícola segue-se por um caminho onde já se podia apreciar a paisagem característica da serra catarinense, como também as organizadas áreas de cultivo, que contam com seis variedades de uvas tintas e duas brancas. A parte externa da edificação é harmonizada por um florido jardim com chafariz, calçadas e bancos, formando uma praça de plena contemplação da paisagem natural e edificada que se fundem na paisagem turística.

A Villa Francioni rapidamente se fez atração entre os moradores e como um ícone de São Joaquim se transformou em destacada imagem turística, não só para a cidade, como também para o Estado (ACORDE, 2009). A figura 4 demonstra o cenário em que está inserida a Vinícola.

O êxito do empreendimento promoveu o interesse de novos investidores, que se estabeleceram na região, aumentando significativamente a produção de vinhos de qualidade, como também se integraram aos roteiros de degustação de vinhos premiados, visitação ao sistema produtivo e contemplação da paisagem turística.

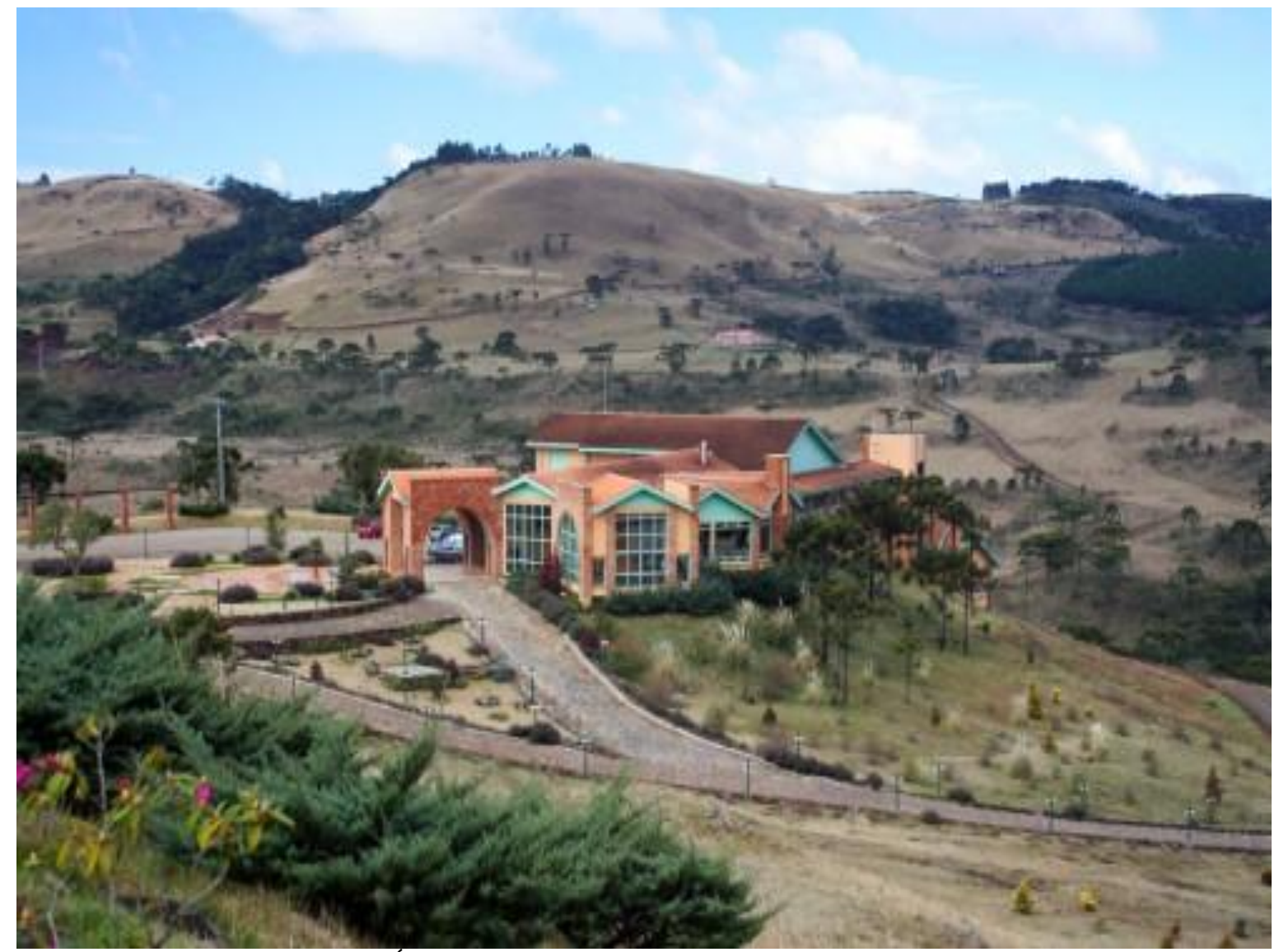

FIGURA 4 - PAISAGEM TURÍSTICA - VINICOLA VILLA FRANCIONI. FONTE: OS AUTORES (2012). 
Pode-se afirmar que a dinâmica que o enoturismo tende a propor como atividade de crescente desenvolvimento econômico em São Joaquim provoca a preocupação com a área urbana do município, pois esta cumpre fundamental papel no acolhimento, orientação e fidelização dos turistas.

Observou-se que as edificações da cidade, em grande parte, estavam mantendo as características originais trazidas pelos colonizadores, caracterizando a época em que foram construídas. Bem como, que toda a região central integrava boa arborização e espaços públicos abertos, no entanto clamando por melhores cuidados com seu sistema de equipamentos públicos, envolvendo manutenção de vias e calçadas, sinalização, iluminação, drenagem pluvial, saneamento, entre outras melhorias que visem dar melhor qualidade de vida a população residente e maior índice de competividade turística ao município.

Como importante símbolo paisagístico de São Joaquim, teve-se como afirmar que a vinícola Villa Francioni é um destacado espaço de memória, pioneirismo e visitação do município, notadamente pela sua beleza cênica e pela produção de vinhos qualificados.

\section{CONCLUSÃO}

Através da pesquisa se atestou o significado desta paisagem para os residentes e o seu potencial de atratividade para os visitantes, não só pela singularidade edificada, mas também por sua identidade com a história e cultura de São Joaquim.

A paisagem turística, com destaque para a área estudada, possui símbolos que permitem descobrir a cidade, sua história, sua cultura e seus costumes, e que são de fácil interpretação pelos turistas.

Identificou-se que a via pública de acesso a vinícola Villa Francioni e a área urbana do município estavam passando por uma fase que inspirava cuidados. $\mathrm{O}$ trajeto em conjunto com a cidade, não estavam oferecendo dispositivos que fizessem com que as pessoas não apenas se movimentassem, mas também permanecessem realizando alguma atividade, convivendo e interagindo com as tradições do município. Considerou-se ser necessário instalar comunicação visual, iluminação, passarelas, 
rampas, bancos, floreiras e lixeiras, trazendo no mobiliário a influência cultural presente no município, transformando, dessa maneira, o território em área de apropriação visual, embelezando o espaço, deixando-o mais agradável e seguro para a convivência, onde os moradores se identifiquem e os turistas se impressionem.

A proposta seria a de requalificar a cidade e o seu entorno. Partindo do cenário provocado pela vinícola Villa Francioni, revitalizar os acessos de entrada e saída do município, criando mirantes de contemplação, reabilitando as pistas de rolamento, adequando os acostamentos para áreas protegidas de circulação de pedestres e ciclistas, com base nos dispositivos de acessibilidade, inserindo serviços de manutenção e conservação continuada, fazendo com que tais vias sejam a extensão da cidade.

No que tange a requalificação da cidade a tarefa é mais complicada, pelo fato de os imóveis pertencerem a particulares e a capacidade de interferência do poder público, nesses casos, ser limitada. Mas considera-se que é preciso tentar, encontrando programas de incentivo e adequação do uso e ocupação do solo que permitam a recuperação e reocupação do espaço, provocando um novo perfil organizacional para as atividades de serviço e comércio, fazendo com que a paisagem urbana não deixe de se transformar, de forma mais agradável e versátil, em um atrativo turístico expressivo, reforçando e se integrando a composição da paisagem turística.

Constatou-se haver por parte do poder público municipal um envolvimento tímido no que diz respeito ao desenvolvimento da atividade turística, tanto mais quando voltado ao enoturismo e, destacadamente quando comparado com o envolvimento empresarial e as representações do governo federal e estadual. Defende-se que a Prefeitura lidere o processo de gestão, não apenas para manter os eventos turísticos existentes, mas principalmente para revitalização dos espaços públicos, gerando e atraindo empreendimentos e investidores para as áreas contíguas.

São Joaquim com sua mistura étnica intrigante detém um patrimônio histórico, cultural, artístico, possuindo belezas naturais e edificadas, compondo uma paisagem turística bastante favorável ao seu desenvolvimento, o que foi observado e caracterizado nos estudos realizados através da vinícola Villa Francioni.

Portanto, a partir da pesquisa considera-se ter-se destacado que a imponência da vinícola Villa Francioni se apresenta, de forma estratégica e democrática, para provocar forte influência na paisagem turística de São Joaquim, que, por conseguinte, pode 
agregar maior valor ao produto turístico da cidade através do enoturismo, desde que haja vontade política de integrar a cidades e seus arredores.

\section{REFERÊNCIAS}

ACORDE - Ação Conjunta de Revitalização e Desenvolvimento. Projeto Acorde São Joaquim. Florianópolis: Governo de Santa Catarina, 2009.

ANJOS, F. A.; ANJOS, S. J. G.; BARROS, R. B.; ZANCHI, C. Processo de planejamento e gestão de territórios turísticos: princípios norteadores de uma proposta. Turismo - Visão e Ação, v. 7, n. 2, p. 377-386, mai./ago. 2005. Disponível em: <http:// www6.univali.br/seer/index.php/rtva/article/view/533/460>. Acesso em: maio/2014.

BENI, M. C. Análise estrutural do turismo. São Paulo: Senac - São Paulo, 2002.

BERTONCINI, S. S. Acorde São Joaquim: identidade local e vocação turística. 80 f. Dissertação (Mestrado em Planejamento Territorial e Desenvolvimento Socioambiental). Florianópolis: UDESC, 2011.

BESSA, A. M.; BENEDICTO, D. B. M.; ALVARES, L. C.; TEIXEIRA, L. A. A. Políticas urbanas para o turismo e suas consequências nas paisagens e culturas locais: $\mathrm{o}$ caso recente do Rio de Janeiro. In: ENCONTRO NACIONAL DE ENSINO DE PAISAGISMO EM ESCOLAS DE ARQUITETURA E URBANISMO NO BRASIL, 9, 2008. Curitiba: Anais..., 2008.

BLUME, R.; HOFF, D. N.; PEDROZO, E. A. Potencialidade competitiva e recursos essenciais à produção de vinhos finos: um estudo da vitivinicultura em São Joaquim, SC. XLV CONGRESSO DA SOCIEDADE BRASILEIRA DE ECONOMIA, ADMINISTRAÇÃO E SOCIOLOGIA RURAL - SOBER "CONHECIMENTOS PARA AGRICULTURA DO FUTURO". Julho, 2007. Disponível em: <http://www.sober.org.br/palestra/6/692.pdf>. Acesso em: maio/2014.

BOULLÓN, R. C. Planificación del espacio turístico. México: Trilhas, 1990.

Planejamento do espaço turístico. Bauru: Edusc, 2002.

CASTROGIOVANNI, A. C. Turismo e ordenação no espaço urbano. In: Turismo Urbano. São Paulo: Contexto, 2001.

Porque geografia no turismo? Um exemplo de caso. Porto Alegre. In: GASTAL, S. Turismo: 9 propostas para um saber-fazer. Porto Alegre: EDIPUCRS, 2002. 
CORDEIRO, W. A vitivinicultura em São Joaquim - SC: uma nova atividade no município. 145 f. Dissertação (Mestrado em Agroecossistemas). Florianópolis: UFSC, 2006.

DALLANHOL, E. B.; TONINI, H. Enoturismo. São Paulo: Aleph, 2012.

DE OLIVEIRA, J. Turismo - Visão e Ação/Universidade do Vale do Itajaí, Curso de Mestrado e Hotelaria. Glossário. Itajaí: Editora UNIVALI, 1999.

DE OLIVEIRA, J.; FERNANDES, D. L.; STACH, C. A paisagem urbana como recurso turístico: um estudo da paisagem edificada de Irati - PR enquanto atrativo turístico. In: Turismo - Visão e Ação, v. 9, n. 1, p. 83-94, jan./abr. 2007. Disponível em: <http://www6.univali.br/seer/index.php/rtva/article/view/222/192>. Acesso em: maio/2014.

DUBRULE, P. L'oenotourisme: une valorisation des produits et du patrimoine vitivinicoles. Paris: Ministère de l'agriculture et de la pêche, 2007.

FRANÇA JR., R. T.; SILVA, C. IDEMi Integração para a Inovação: artigos selecionados II Conferência Internacional de Integração do Design, Engenharia e Gestão para Inovação. Florianópolis: Editora UDESC, 2012, p-32-47

HALL, C.; SHARPLES, L.; CAMBOURNE, B.; MACIONIS, N. Wine tourism around the world: development, management and markets. Oxford: Butterworthheinemann, 2000.

IBGE. Instituto Brasileiro de Geografia e Estatística. Censo 2010. Disponível em: $<$ http://www.ibge.gov.br/home/>. Acesso em: maio/2014.

LOHMANN, G.; PANOSSO NETO, A. Teoria do turismo: conceitos, modelos e sistemas. São Paulo: Aleph, 2008.

LOMBARDO J. A. Santa Catarina à mesa: a revolução das uvas e do vinho e o renascimento das cervejarias no estado. Florianópolis: Expressão, 2009.

LOSSO, F. B. A produção de vinhos finos de altitude na região vitivinícola de São Joaquim (SC): uma alternativa para o turismo. 206 f. Dissertação (Mestrado de Turismo e Hotelaria). Balneário Camboriú: UNIVALI, 2010.

LYNCH, K. A Imagem da cidade. São Paulo: Martins Fontes, 1997.

RODRIGUES NETO, J. A. Memórias de um Joaquinense. Florianópolis: ALESC, 2011.

SEBRAE - Serviço de Apoio a Micro e Pequenas Empresas. Santa Catarina em números - São Joaquim. Florianópolis: Sebrae/SC, 2013. 
SERRENHO, M.; ÁGUAS, P. O perfil do enoturista. Revista ESGHT/UALG, n. 15, p. 21-30, 2006.

SILVA, M. G. L. Cidades turísticas: identidades e cenários de lazer. São Paulo, Aleph, 2004.

SOARES, J. G.; CARDOZO, P. F. A avaliação e hierarquização de atrativos turísticos como ferramenta para o planejamento turístico. São Paulo: Revista Partes, 2008. Disponível em: < http://www.partes.com.br/turismo/poliana/avaliacao.asp>. Acesso em: maio/2014.

YÁZIGI, E. A Importância da Paisagem. In: Turismo e Paisagem. In: YÁZIGI, E. (org.) São Paulo: Contexto, 2002, p. 11-28.

Recebido em: 15-05-2014.

Aprovado em: 13-06-2014. 